\title{
Evaluation of Cortical Microarchitecture and Biomechanical Properties 6-12 Months after Atypical Femoral Fracture
}

\author{
Mariana O Perez ${ }^{1}$, Diogo S Domiciano ${ }^{1}$, Vanda Jorgetti ${ }^{2}$ and Rosa MR Pereira*1 \\ ${ }^{1}$ Bone Laboratory Metabolism, Rheumatology Division, Hospital das Clinicas HCFMUSP, Brazil \\ ${ }^{2}$ Nephrology Division, Hospital das Clinicas HCFMUSP, Brazil \\ *Corresponding author: Dra Rosa Maria R. Pereira, Rheumatology Division, Faculty of Medicine, University of Sao Paulo, \\ São Paulo, SP, 01246-903, Brazil
}

\begin{tabular}{|c|c|}
\hline ARTICLE INFO & ABSTRACT \\
\hline Received: 玤 March 09, 2020 & Atypical Femoral Fractures (AFF) are low energy femoral fractures associated with \\
\hline Published: March 17, 2020 & $\begin{array}{l}\text { long-term bisphosphonate therapy. Our aim was to evaluate the cortical bone parameters } \\
\text { and biomechanical proprieties by high-resolution peripheral quantitative computed }\end{array}$ \\
\hline $\begin{array}{l}\text { Citation: Mariana O P, Diogo S D, Vanda J, } \\
\text { Rosa MR P. Evaluation of Cortical Microar- } \\
\text { chitecture and Biomechanical Properties } \\
6 \text { 6-12 Months after Atypical Femoral Frac- } \\
\text { ture. Biomed J Sci \& Tech Res 26(4)-2020. } \\
\text { BJSTR. MS.ID.004385. }\end{array}$ & $\begin{array}{l}\text { 6-12 months after AFF. Twelve patients with AFF were evaluated. Cortical volumetric } \\
\text { bone mineral density (Ct.vBMD), cortical thickness (Ct.Th), cortical porosity (Ct.Po), } \\
\text { Stiffness (S) and failure load (F.Load) were assessed by HR-pQCT. Histomorphometry of } \\
\text { transiliac bone biopsy evaluated Ct.Th, Ct.Po and bone remodeling. All bone parameters } \\
\text { were compared with healthy controls. The mean age of the patients was } 60.5 \pm 12.8 \\
\text { years, } 91.6 \% \text { women, } 91.6 \% \text { used BPs (median: } 6 \text { years[1-10yr]). Rheumatic diseases } \\
\text { were observed in } 50 \% \text { patients and glucocorticoid (GC) use in } 41.6 \% \text {. At distal tibia and }\end{array}$ \\
\hline $\begin{array}{l}\text { Keywords: Atypical Femoral Fracture; Cor- } \\
\text { tical Microarchitecture; Bone Stiffness; HR- } \\
\text { pQCT; Bone Histomorphometry }\end{array}$ & $\begin{array}{l}\text { radius, Ct.vBMD was low/normal in } 66.6 \% \text {, Ct.Th low/normal in } 77.7 \% \text { and Ct.Po high/ } \\
\text { normal in more than } 66.6 \% \text {. More than } 50 \% \text { of the patients had low } \mathrm{S} \text { and F.Load at these } \\
\text { sites. S and F.Load were positively correlated with Ct.Th }(\mathrm{r}=0.724, \mathrm{p}=0.028 ; \mathrm{r}=0.718 \text {, } \\
\mathrm{p}=0.02 \text {, respectively) at tibia. At radius, } \mathrm{S} \text { and F.Load were also positively correlated with } \\
\text { Ct.Th ( } \mathrm{r}=0.735, \mathrm{p}=0.024 ; \mathrm{r}=0.717, \mathrm{p}=0.030 \text {, respectively). Iliac crest histomorphometry } \\
\text { exhibited low Ct.Th in } 60 \% \text {, low Ct.Po in } 100 \% \text {, and suppressed bone remodeling in } 100 \% \\
\text { of patients. Our data demonstrated that among patients with AFF, rheumatic diseases } \\
\text { and GC use are common. Cortical and strength bone parameters were deteriorated at } \\
\text { distal tibia/radius and iliac crest, suggesting the presence of significant bone fragility } \\
\text { after } 6-12 \text { months of AFF follow-up. }\end{array}$ \\
\hline
\end{tabular}

\section{Introduction}

Atypical femoral fractures (AFF) are low-energy fractures located in the subtrochanteric or diaphyseal femoral region and associated mainly with the long-term use of bisphosphonates (BPs) [1,2]. There is a direct association between the duration of BP exposure and the risk of AFF, especially beyond 5 years $[3,4]$. The pathogenesis of AFF remains unclear. Prior studies have focused primarily on the role of bone remodeling suppression associated with the use of BPs. In addition, it is known that BPs alter the biomechanical properties of bone tissue because they interfere in collagen cross-link ing, advanced glycation, mineralization and angiogenesis, favoring the accumulation of microdamage [2,3]. Moreover, glucocorticoid use and rheumatic disease has been associated with AFF [4-7]. Sato et al. previously reported a high frequency (8\%) of femoral localized reaction (localized periosteal thickening of the lateral cortex, beaking) in patients with autoimmune diseases taking BPs and GC [5]. In studies by Thompson et al. [6] and Dell et al. [4], AFF occurred, respectively, in $27 \%$ and $12 \%$ of patients on GC therapy. In addition, Girgis et al. reported that rheumatoid arthritis and use of glucocorticoids were risk factors for AFF [7]. 
Typically, patients with AFF demonstrate some peculiar findings, such as prodromal thigh pain for weeks to months prior to the fracture, minimal or no trauma, transverse or short oblique configuration, and little or noncomminuted and bilateral fractures (either simultaneous or sequential) [1,2]. Moreover, patients with AFF exhibit cortical bone thickening and periosteal reaction on radiographs of the femoral shaft [2], suggesting that AFF may occur due to cortical stress. The cortical bone exerts an important role in bone stiffness and contributes to whole bone mechanical competence. In fact, cortical thickness is a strong predictor of bone strength and resistance to fracture $[8,9]$. Recently, the involvement of cortical bone has been studied and assessed by new imaging methods such as high-resolution peripheral quantitative computed tomography (HR-pQCT) [10] and bone histomorphometry [11]. HR-pQCT is a noninvasive technique that assesses separately the cortical and trabecular components at peripheral sites such as the distal tibia and radius. HR-pQCT is a method for assessing bone microarchitecture and bone stiffness [10]. Bone histomorphometry is the quantitative histological analysis of the bone obtained from transiliac bone biopsies and is the gold standard in the static and dynamic evaluation of bone parameters. It has recently been used to evaluate the cortical compartment $[11,12]$. No study has evaluated cortical microstructure and bone strength parameters using HR-pQCT and bone histomorphometry assessments. Therefore, the aim of this study is to evaluate patients with AFF after 6-12 months of follow-up, from a rheumatology service, with emphasis on (1) the cortical bone microarchitecture and bone strength parameters using HR-pQCT and (2) the cortical parameters by iliac crest histomorphometry.

\section{Materials and Methods}

\section{Study Design}

This study had the approval of the Ethics Committee of the University of Sao Paulo. We conducted a cross-sectional, case-control study of 12 subjects who met the AFF criteria according to the American Society for Bone and Mineral Research (ASBMR) [2] and were regularly followed-up at the outpatient Osteometabolic Diseases and Osteoporosis, Rheumatology Service, Clinics Hospital of the University of Sao Paulo between January 2010 and December 2018. The demographic and clinical data, including race, age, BP indication, BP duration, clinical manifestations of AFF, diagnosis of rheumatic disease, glucocorticoid (GC) use and treatment post-AFF were obtained through interviews with the patients and reviews of their medical records. The bone parameters obtained by dual-energy X-ray absorptiometry (DXA), HR-pQCT and iliac crest biopsy histomorphometry were evaluated 6-12 months after AFF.

\section{Atypical Femoral Fracture}

AFF was defined according to the second report of the ASBMR Task Force 2013 [2]. All five major criteria were required for the definition of AFF: (1) located anywhere along the femur from just distal to the lesser trochanter to just proximal to the supracondy- lar flare, (2) minimal trauma, (3) noncomminuted or minimally comminuted, (4) fracture line originating at the lateral cortex and substantially transverse in orientation and (5) complete fractures that may have medial spikes, incomplete only involving the lateral cortex. The following minor criteria, although not decisive for the diagnosis, were also evaluated: the presence of localized periosteal or endosteal thickening of the lateral cortex ("beaking" or "flaring"), prodromal symptoms such as pain in the groin or thigh and bilateral fractures [2].

\section{Reference Curves of Healthy Individuals of HR-pQCT and Histo- morphometric Parameters}

Patients' parameters obtained using HR-pQCT were compared to data from a HR-pQCT reference curve of Brazilian healthy individuals, according to sex and age [10]. Moreover, patients' histomorphometric static parameters were compared to histomorphometric variables from a reference curve of Brazilian healthy individuals [13], and the dynamic variables were compared to Melsen et al data [14], according to sex and age.

\section{Radiological Assessment}

Two rheumatologists (MOP and DSD) independently evaluated the bilateral femoral radiographs in accordance with the ASBMR definition [2]. Subtrochanteric or femoral shaft fracture sites were assessed. Major features such as complete fracture and the presence or absence of a medial spike were evaluated, considering also that focal cortical thickening and a transverse fracture on the lateral side are the elements with a high accuracy for the diagnosis of AFF $[2,15]$. When the two rheumatologists had discordant evaluations, another rheumatologist (RMRP) made the final decision after an independent evaluation. A technetium bone scintigraphy or magnetic resonance imaging were performed to detect bilateral AFF when there was no visible radiographic alteration in the contralateral femur [15].

\section{Bone Mineral Density Measurement}

BMD was analyzed by dual-energy X-ray absorptiometry (DXA; Hologic; QDR 4500, Bedford, MA, USA) at the lumbar spine (L1-L4), total hip and femoral neck contralateral to the atypical femur fracture. In patients who presented with bilateral AFF, only the lumbar spine was analyzed. Osteoporosis was defined by a T-score $\leq-2.5 \mathrm{SD}$ and osteopenia by T-score between -1.0 and -2.5 , according to the World Health Organization [16]. The least significant change (LSC) for BMD measurements was $0.033 \mathrm{~g} / \mathrm{cm} 2$ at the lumbar spine, $0.047 \mathrm{~g} / \mathrm{cm} 2$ at the femoral neck, and $0.039 \mathrm{~g} / \mathrm{cm} 2$ at the total hip.

\section{High-Resolution Peripheral Quantitative Computed Tomogra- phy (HR-pQCT)}

HR-pQCT at the distal tibia and radius were assessed in 9 AFF patients and compared with Brazilian healthy subjects from a reference curve matched by age and sex [10]. HR-pQCT scans (XtremeCT, 
SCANCO Medical, Switzerland) were performed after immobilizing the nondominant distal tibia and forearm in a carbon fiber shell as previously described [17]. The region of interest was defined on a scout film by manual placement of a reference line at the endplate of the tibia or radius, with the first slice $22.5 \mathrm{~mm}$ and $9.5 \mathrm{~mm}$ proximal to the reference line at the tibia and radius, respectively [1719]. The standard protocol for image acquisition and analyses was applied, and a detailed description of the measurement protocol at our center was previously described [17]. The standard and advanced cortical (auto segmentation) methods of the scanner were used for the analysis with appropriate references $[10,20]$. All examinations were conducted by a trained biomedical scientist (JCA), who also carefully examined each scan for motion artifacts. In the case of significant motion artifacts, a second examination was performed (by RMRP). All HR-pQCT images were scored based on a motion scale ranging from 0 (no movement) to 4 (significant blurring of the periosteal surface, discontinuities in the cortical layer) [21]. For this study, scans with a score of 4 were excluded. Quality control was monitored daily using a phantom calibration provided by the manufacturer. The parameters of cortical bone microarchitecture evaluated were the cortical volumetric bone mineral density (Ct.vBMD [mg HA/cm3]), cortical thickness (Ct.Th [mm]) and cortical porosity index (Ct.Po [1]) [22]. Micro-finite element analysis ( $\mu \mathrm{FEA})$ - To assess the biomechanical bone strength, linear $\mu \mathrm{FE}$ models of the distal tibia and radius were created directly from the HR-pQCT images using finite element analysis software (Scanco Medical AG). The biomechanical properties studied were the bone stiffness ( $\mathrm{S}[\mathrm{N} / \mathrm{mm}]$ ), and estimated failure load (F.Load $[\mathrm{kN}])[17,23]$.

\section{Transiliac Bone Biopsy}

Five patients with AFF underwent transiliac bone biopsy. All patients received double tetracycline labeling before the biopsy (20 $\mathrm{mg} / \mathrm{kg} /$ day for 3 days, administered in two separate doses, separated by an interval of 10 days). The biopsies were performed 3-5 days after the last dose of tetracycline under local anesthesia and light sedation. Bone samples of approximately $1.5 \mathrm{~cm}$ in length were obtained from the anterior iliac bone using an electric trephine (Gaulthier Medical, Rochester, MN, USA).

\section{Bone Histomorphometry}

The bone fragments were composed of two cortices (internal and external). Bone material designated for histomorphometry was fixed in $70 \%$ ethanol and processed according to Malluche and Faugere [24]. Using a Polycut S equipped with a tungsten carbide knife (Leica, Heidelberg, Germany), nondecalcified bones were cut into $5 \mu \mathrm{m}$ and $10 \mu \mathrm{m}$ thick sections. Static histomorphometric data were obtained using the software Osteomeasure (Osteometrics Inc., Atlanta, GA, USA). Unstained $10 \mu \mathrm{m}$ tissue slices were prepared for analysis of the dynamic parameters under a microscope with ultraviolet light. All biopsies were coded, and the histomorphomet- ric analysis was performed blindly by two observers (VJ and MOP). All histomorphometric data are described according to the ASBMR nomenclature [11]. The histomophometric parameters evaluated were as follows:

a) Histomophometric Cortical Parameter: Both cortices were analyzed, and the results for each cortex were averaged. Cortical thickness (Ct.Th [um]) and cortical porosity (Ct.Po [\%]) were evaluated. Cortical thickness is the mean thickness of the inner and outer cortex. Cortical porosity was calculated based on the total Haversian canal area as a percentage of the total cortical area [25-27].

b) Histomorphometric kinetic Parameter: the bone formation rate (BFR/BS $[\mu \mathrm{m} 3 / \mu \mathrm{m} 2 /$ day]) is the amount of new bone formed in unit per unit of bone surface (BS). The patients were classified according to BFR/BS into high bone remodeling (BFR/BS values greater than 1 standard deviation (SD) above the normal range) or low bone remodeling (BFR/BS values greater than 1 SD below the normal range). The absence of double labeling by tetracycline makes it impossible to evaluate BFR/BS. Patients who did not present double labeling were classified as very low bone remodeling [28].

\section{Statistical Analysis}

Statistical analysis of the pooled data was performed using Statistical Package for the Social Science software version 20.0 (SPSS, Inc., Chicago, IL, USA). The results are presented as the means \pm $\mathrm{SD}$, median (range) or as a proportion. The measures of correlation were analyzed according to the Spearman and Pearson correlation coefficients ( $r$ ). p values less than 0.05 were considered statistically significant.

\section{Results}

Twelve patients with AFF were evaluated. The clinical characteristics of patients are shown in Table 1 . The mean age of the patients was $60.5 \pm 12.8$ years old; $91.6 \%$ were women and $83.3 \%$ Caucasian. At the time of fracture, $91.6 \%$ used BPs, with a median BP use of 6 years (range, 1-10 years). Approximately seventy-seven percent of patients were on alendronate. One patient was on denosumab but had received BP for 6 years before starting denosumab. In all patients, the use of antiresorptive therapy was indicated due to their osteoporosis diagnosis. All AFF were associated with minimal trauma, and $75 \%$ of the patients reported thigh pain before the AFF. Rheumatic diseases were observed in $50 \%$ of the patients, most of them with rheumatoid arthritis. Approximately $42 \%$ of the patients used oral glucocorticoid, with a median prednisone dose of $5 \mathrm{mg}$ /day (range, 5-10 mg/day). All patients presented with a diaphyseal fracture, of which 11 (91.6\%) were complete fracture and $2(16.6 \%)$ were bilateral. Typically, the fractures were noncomminuted and originated at the lateral cortex with a transverse orientation. 
Table 1: Clinical characteristics of twelve patients with atypical femoral fracture.

\begin{tabular}{|c|c|}
\hline Clinical characteristics & n (\%) \\
\hline Female, $\mathrm{n}(\%)$ & $11(91.6)$ \\
\hline Caucasian, $\mathrm{n}(\%)$ & $10(83.3)$ \\
\hline Age, years \pm SD & $60.5 \pm 12.8$ \\
\hline Previous osteoporosis, $\mathrm{n}(\%)$ & $12(100)$ \\
\hline Prodromal thigh pain, $\mathrm{n}(\%)$ & $9(75)$ \\
\hline Antiresorptive drugs & $12(100)$ \\
\hline Bisphosphonate, $\mathrm{n}(\%)$ & $11(91.6)$ \\
\hline Alendronate, $\mathrm{n}(\%)$ & $8(66.6)$ \\
\hline Duration of bisphosphonate use, years* & $6(1-10)$ \\
\hline Denosumab, $\mathrm{n}(\%)$ & $1(8.3)$ \\
\hline Rheumatic diseases, $\mathrm{n}(\%)$ & $6(50)$ \\
\hline Rheumatoid arthritis, $\mathrm{n}(\%)$ & $2(16.6)$ \\
\hline Sjögren's Syndrome, $\mathrm{n}(\%)$ & $1(8.3)$ \\
\hline Behçet's disease, $\mathrm{n}(\%)$ & $1(8.3)$ \\
\hline Inclusion body myopathy, $\mathrm{n}(\%)$ & $1(8.3)$ \\
\hline Adult-onset Still's disease, $\mathrm{n}(\%)$ & $1(8.3)$ \\
\hline Glucocorticoid use, $\mathrm{n}(\%)$ & $5(41.6)$ \\
\hline Glucocorticoid dose, $\mathrm{mg} /$ dia* & $5(5-10)$ \\
\hline
\end{tabular}

*Data expressed as median (range)

Table 2: Cortical microarchitecture data at distal tibia and radius assessed by HR-pQCT of nine patients with atypical femoral fracture, compared with reference curve of Brazilian healthy subjects (according sex and age) [10].

\begin{tabular}{|c|c|c|c|c|c|c|c|c|c|}
\hline & $\begin{array}{c}\text { Ct.vBMD, } \\
\text { mmHA/ } \\
\text { cm3 } \\
\text { Patients }\end{array}$ & $\begin{array}{c}\text { Ct.vBMD, } \\
\text { mmHA/ } \\
\text { cm3 } \\
\text { Brazilian } \\
\text { healthy } \\
\text { subjects }\end{array}$ & $\begin{array}{c}\text { Ct.vBMD, } \\
\text { mmHA/ } \\
\text { cm3 } \\
\text { Patients }\end{array}$ & $\begin{array}{c}\text { Ct.Th, } \\
\text { mm } \\
\text { Patients }\end{array}$ & $\begin{array}{l}\text { Ct.Th, } \\
\text { mm } \\
\text { Brazilian } \\
\text { healthy } \\
\text { subjects }\end{array}$ & $\begin{array}{c}\text { Ct.Th, } \\
\text { mm } \\
\text { Patients }\end{array}$ & $\begin{array}{c}\text { Ct.Po, } \\
1 \\
\text { Patients }\end{array}$ & $\begin{array}{c}\text { Ct.Po, } \\
1 \\
\text { Brazilian } \\
\text { healthy } \\
\text { subjects }\end{array}$ & $\begin{array}{c}\text { Ct.Po, } \\
1 \\
\text { Patients }\end{array}$ \\
\hline \multicolumn{10}{|c|}{ DISTAL TIBIA } \\
\hline$\# 1$ & 1006 & $\begin{array}{c}1003(975- \\
1032)\end{array}$ & Normal & 0.84 & $\begin{array}{c}1.20(1.01- \\
1.39)\end{array}$ & Low & 0.012 & $\begin{array}{c}0.028 \\
(0.022- \\
0.035)\end{array}$ & Low \\
\hline$\# 2$ & 796 & $\begin{array}{c}830 \text { (806- } \\
882)\end{array}$ & Low & 0.77 & $\begin{array}{c}1.12(0.93- \\
1.31)\end{array}$ & Low & 0.075 & $\begin{array}{c}0.075 \\
(0.059- \\
0.092)\end{array}$ & Normal \\
\hline \# 3 & 894 & $\begin{array}{c}830 \text { (806- } \\
882)\end{array}$ & High & 1.09 & $\begin{array}{c}1.12(0.93- \\
1.31)\end{array}$ & Normal & 0.086 & $\begin{array}{c}0.075 \\
(0.059- \\
0.092)\end{array}$ & Normal \\
\hline$\# 4$ & 943 & $\begin{array}{c}1003(975- \\
1032)\end{array}$ & Low & 0.82 & $\begin{array}{c}1.20(1.01- \\
1.39)\end{array}$ & Low & 0.05 & $\begin{array}{c}0.028 \\
(0.022- \\
0.035) \\
\end{array}$ & High \\
\hline$\# 5$ & 870 & $\begin{array}{c}830(806- \\
882)\end{array}$ & Normal & 1.33 & $\begin{array}{c}1.12(0.93- \\
1.31)\end{array}$ & High & 0.106 & $\begin{array}{c}0.075 \\
(0.059- \\
0.092)\end{array}$ & High \\
\hline$\# 6$ & 795 & $\begin{array}{c}830(806- \\
882)\end{array}$ & Low & 0.77 & $\begin{array}{c}1.12(0.93- \\
1.31)\end{array}$ & Low & 0.087 & $\begin{array}{c}0.075 \\
(0.059- \\
0.092)\end{array}$ & Normal \\
\hline \# 7 & 937 & $\begin{array}{c}970(943- \\
1005)\end{array}$ & Low & 1.04 & $\begin{array}{c}1.19(0.98- \\
1.32)\end{array}$ & Normal & 0.049 & $\begin{array}{c}0.045 \\
(0.031- \\
0.059) \\
\end{array}$ & Normal \\
\hline \# 8 & 952 & $\begin{array}{c}\text { 871(827- } \\
893)\end{array}$ & High & 1.44 & $\begin{array}{c}1.18(1.09- \\
1.29)\end{array}$ & High & 0.054 & $\begin{array}{c}0.068 \\
(0.048- \\
0.080)\end{array}$ & Normal \\
\hline
\end{tabular}




\begin{tabular}{|c|c|c|c|c|c|c|c|c|c|}
\hline \# 9 & 1002 & $\begin{array}{c}903(873- \\
934)\end{array}$ & High & 1.19 & $\begin{array}{c}1.14(0.91- \\
1.31)\end{array}$ & Normal & 0.023 & $\begin{array}{c}0.071 \\
(0.054- \\
0.081) \\
\end{array}$ & Low \\
\hline \multicolumn{10}{|c|}{ DISTAL RADIUS } \\
\hline \# 1 & 1129 & $\begin{array}{c}1023(971- \\
1044)\end{array}$ & High & 1.31 & $\begin{array}{c}0.86(0.68- \\
0.99)\end{array}$ & High & 0.003 & $\begin{array}{c}0.013 \\
(0.010- \\
0.017)\end{array}$ & Low \\
\hline \# 2 & 926 & $\begin{array}{c}925(868- \\
972)\end{array}$ & Normal & 0.84 & $\begin{array}{c}0.78(0.63- \\
0.87)\end{array}$ & Normal & 0.033 & $\begin{array}{c}0.027 \\
(0.022- \\
0.034)\end{array}$ & Normal \\
\hline \# 3 & 960 & $\begin{array}{c}925 \text { (868- } \\
972)\end{array}$ & Normal & 0.68 & $\begin{array}{c}0.78(0.63- \\
0.87)\end{array}$ & Normal & 0.038 & $\begin{array}{c}0.027 \\
(0.022- \\
0.034)\end{array}$ & High \\
\hline \# 4 & 912 & $\begin{array}{c}1023(971- \\
1044)\end{array}$ & Low & 0.43 & $\begin{array}{c}0.86(0.68- \\
0.99)\end{array}$ & Low & 0.016 & $\begin{array}{c}0.013 \\
(0.010- \\
0.017)\end{array}$ & Normal \\
\hline \# 5 & 1002 & $\begin{array}{c}925 \text { (868- } \\
972)\end{array}$ & High & 0.76 & $\begin{array}{c}0.78(0.63- \\
0.87)\end{array}$ & Normal & 0.033 & $\begin{array}{c}0.027 \\
(0.022- \\
0.034) \\
\end{array}$ & Normal \\
\hline \# 6 & 942 & $\begin{array}{c}925 \text { (868- } \\
972)\end{array}$ & Normal & 0.49 & $\begin{array}{c}0.78(0.63- \\
0.87)\end{array}$ & Low & 0.015 & $\begin{array}{c}0.027 \\
(0.022- \\
0.034)\end{array}$ & Low \\
\hline \# 7 & 947 & $\begin{array}{c}1002(979- \\
1049)\end{array}$ & Low & 0.75 & $\begin{array}{c}0.85(0.69- \\
0.99)\end{array}$ & Normal & 0.026 & $\begin{array}{c}0.016 \\
(0.013- \\
0.024)\end{array}$ & High \\
\hline \# 8 & 972 & $\begin{array}{c}839(801- \\
884)\end{array}$ & High & 1.03 & $\begin{array}{c}0.72(0.59- \\
0.88)\end{array}$ & High & 0.035 & $\begin{array}{c}0.024 \\
(0.019- \\
0.032)\end{array}$ & High \\
\hline \# 9 & 1004 & $\begin{array}{c}968(932- \\
1016)\end{array}$ & Normal & 0.91 & $\begin{array}{c}0.83(0.72- \\
0.91)\end{array}$ & Normal & 0.017 & $\begin{array}{c}0.025 \\
(0.022- \\
0.029)\end{array}$ & Low \\
\hline
\end{tabular}

One patient presented with an incomplete fracture characterized by the presence of localized periosteal lesion of the lateral cortex ("beaking"). All patients showed cortical thickening at the femoral diaphysis. Six patients (50\%) underwent the hip analysis (total hip and femoral neck) at the contralateral site of the AFF by DXA. The other 6 patients had the analysis only at the lumbar spine as a result of the involvement of the contralateral femur due to femoral neck fracture ( 4 patients) or bilateral AFF ( 2 patients). DXA analysis showed that most of the patients had osteopenia both at the hip and lumbar spine. None of the patients had T-score $\leq-2.5$ SD at the total hip; only $16 \%$ did at the femoral neck and $25 \%$ at the lumbar spine. HR-pQCT at the distal tibia and radius was performed in nine (75\%) patients. Compared to the reference curve from Brazilian healthy subjects [10] according sex and age, HR-pQCT at both sites (distal tibia and radius [ $\mathrm{n}=9$ ]) showed Ct.vBMD to be normal/low in $66.6 \%$ and Ct.Th to be normal/low in $77.7 \%$ of cases. Ct.Po was normal/high at tibia and radius in $77.7 \%$ and $66.6 \%$ of the patients, respectively (Table 2).

Table 3: Bone stiffness (S) and F.Load at distal tibia and radius assessed by HR-pQCT of nine patients with atypical femoral fracture, compared with Brazilian healthy subjects from a reference curve (according sex and age) [10].

\begin{tabular}{|c|c|c|c|c|c|c|}
\hline & $\begin{array}{c}\mathrm{S}, \mathrm{kN} / \mathrm{mm} \\
\text { Patients }\end{array}$ & $\begin{array}{c}\mathrm{S}, \mathrm{kN} / \mathrm{mm} \\
\text { Brazilian healthy } \\
\text { subjects }\end{array}$ & $\begin{array}{l}\mathrm{S}, \mathrm{N} / \mathrm{mm} \\
\text { Patients }\end{array}$ & $\begin{array}{l}\text { F.Load, N } \\
\text { Patients }\end{array}$ & $\begin{array}{c}\text { F.Load, } \mathbf{N} \\
\text { Brazilian healthy } \\
\text { subjects }\end{array}$ & $\begin{array}{l}\text { F.Load, N } \\
\text { Patients }\end{array}$ \\
\hline \multicolumn{7}{|c|}{ DISTAL TIBIA } \\
\hline$\# 1$ & 106 & $200(178-216)$ & Low & 5250 & $\begin{array}{c}9515(8576- \\
10372)\end{array}$ & Low \\
\hline$\# 2$ & 91 & $166(155-187)$ & Low & 4395 & 7938 (7426-8749) & Low \\
\hline$\# 3$ & 109 & $166(155-187)$ & Low & 5148 & 7938 (7426-8749) & Low \\
\hline$\# 4$ & 148 & $200(178-216)$ & Low & 7010 & $\begin{array}{c}9515 \text { (8576- } \\
10372)\end{array}$ & Low \\
\hline$\# 5$ & 145 & 166 (155-187) & Low & 6876 & 7938 (7426-8749) & Low \\
\hline$\# 6$ & 134 & $166(155-187)$ & Low & 6334 & 7938 (7426-8749) & Low \\
\hline$\# 7$ & 170 & 181 (169-197) & Normal & 8157 & 8699 (8088-9448) & Normal \\
\hline
\end{tabular}




\begin{tabular}{|c|c|c|c|c|c|c|}
\hline \# 8 & 238 & $228(210-274)$ & Normal & 11320 & 8829 (7859-9328) & High \\
\hline \# 9 & 176 & $186(163-196)$ & Normal & 8434 & 8829 (7859-9328) & Normal \\
\hline \multicolumn{7}{|c|}{ DISTAL RADIUS } \\
\hline$\# 1$ & 58 & $79(67-85)$ & Low & 2694 & 3777 (3261-4075) & Low \\
\hline$\# 2$ & 66 & $61(55-68)$ & Normal & 3097 & $2940(2691-3375)$ & Normal \\
\hline \# 3 & 44 & $61(55-68)$ & Low & 2129 & $2940(2691-3375)$ & Low \\
\hline$\# 4$ & 45 & $79(67-85)$ & Low & 2260 & 3777 (3261-4075) & Low \\
\hline$\# 5$ & 52 & $61(55-68)$ & Low & 2496 & $2940(2691-3375)$ & Low \\
\hline \# 6 & 40 & $61(55-68)$ & Low & 1964 & $2940(2691-3375)$ & Low \\
\hline \# 7 & 75 & $71(65-79)$ & Normal & 3607 & 3413 (3204-3838) & Normal \\
\hline \# 8 & 78 & $95(88-109)$ & Low & 3699 & 3199 (2782-3608) & High \\
\hline \#9 & 74 & $66(58-75)$ & Normal & 3611 & 3199 (2782-3608) & High \\
\hline
\end{tabular}

Table 4: Cortical microarchitecture data of five patients with atypical femoral fracture by bone histomorphometry of transiliac biopsy, compared with Brazilian healthy subjects from a reference curve (according sex and age) [13].

\begin{tabular}{|c|c|c|c|c|c|c|}
\hline & $\begin{array}{c}\text { Ct.Th, } \boldsymbol{\mu m} \\
\text { Patients }\end{array}$ & $\begin{array}{c}\text { Ct.Th, } \boldsymbol{\mu m} \\
\text { Brazilian healthy } \\
\text { subjects }\end{array}$ & $\begin{array}{c}\text { Ct.Th, } \boldsymbol{\mu m} \\
\text { Patients }\end{array}$ & $\begin{array}{c}\text { Ct.Po, \% } \\
\text { Patients }\end{array}$ & $\begin{array}{c}\text { Ct.Po, \% } \\
\text { Brazilian healthy } \\
\text { subjects }\end{array}$ & $\begin{array}{c}\text { Ct.Po, \% } \\
\text { Patients }\end{array}$ \\
\hline$\# 1$ & 260 & $561(303-885)$ & Low & 0.86 & $3.66(2.73-5.6)$ & Low \\
\hline$\# 2$ & 275 & $561(303-885)$ & Low & 0.85 & $3.66(2.73-5.6)$ & Low \\
\hline$\# 3$ & 675 & $561(303-885)$ & Normal & 2.32 & $3.66(2.73-5.6)$ & Low \\
\hline$\# 4$ & 389 & $488(416-778)$ & Low & 1.5 & $5.18(4.45-9.92)$ & Low \\
\hline$\# 5$ & 619 & $561(303-885)$ & Normal & 1.21 & $3.66(2.73-5.6)$ & Low \\
\hline
\end{tabular}

Regarding the stiffness parameter at the distal tibia and radius, $66.6 \%$ of the patients had lower S (Table 3), compared to reference curve from Brazilian healthy subjects [10]. These findings were analogous to the F.Load that was low in $66.6 \%$ of patients at the tibia and $55.5 \%$ of patients at the radius compared to the reference curve from Brazilian healthy subjects [10]. At the distal tibia, $\mathrm{S}$ was positively correlated with Ct.Th $(\mathrm{r}=0.724, \mathrm{p}=0.028)$, and at the distal radius, $\mathrm{S}$ was positively correlated with $\mathrm{Ct}$.Th $(\mathrm{r}=0.735$, $\mathrm{p}=0.024)$. At the distal tibia, F.Load was positively correlated with Ct.Th $(r=0.718, p=0.020)$, and at the distal radius, F.Load was positively correlated with Ct.Th $(r=0.717, p=0.030)$. There was no correlation between S and F.Load with Ct.vBMD and Ct.Po. Transiliac bone biopsy was performed in $5(41.6 \%)$ patients. The bone histomorphometry analysis showed lower Ct.Th in $60 \%$ of cases and lower Ct.Po in all patients compared to reference curve from Brazilian healthy subjects [13] (Table 4). As expected, all patients had suppressed bone remodeling, 4 patients showed very low bone remodeling (absence of double labeling by tetracycline, making it impossible to evaluate the BFR/BS) and 1 patient low bone remodeling $(B F R / B S=0.02 \mu \mathrm{m} 3 / \mu \mathrm{m} 2 /$ day, reference curve of healthy subjects $=0.07 \pm 0.03 \mu \mathrm{m} 3 / \mu \mathrm{m} 2 /$ day). Concerning the treatment after AFF, $66.6 \%$ of patients received teriparatide and intramedullary nail fixation; $25 \%$ underwent only intramedullary nail fixation and $8.3 \%$ received only teriparatide. Teriparatide was administered after the HR-pQCT and bone histomorphometric analysis were performed.

\section{Discussion}

To the best of our knowledge, this is the first study to analyze the cortical bone microarchitecture and bone stiffness at peripheral sites by HR-pQCT and the iliac crest bone histomorphometry in patients with AFF. A significant deterioration of the cortical bone and of the bone strength in these AFF patients was observed. This study has several strengths, such as the evaluation of the cortical bone at peripheral sites (distal tibia and radius) using concomitantly HRpQCT and iliac crest bone histomorphometry and the comparison with references curves of HR-pQCT and histomorphometric parameters obtained from healthy Brazilian subjects. Unlike other studies, we assessed the patients during a specific time period (6-12 months after AFF). Although AFF is clearly defined as a complication of long-term antiresorptive therapy with BPs, the median period of BPs use in this study (6 years) was lower than in other studies (8-10 years) $[29,30]$. This difference might be related to the greater risk of fracture of our patients, given the high prevalence of risk factors for osteoporosis and bone fragility in this patient's cohort. Half of the subjects had rheumatic diseases, notably rheumatoid arthritis (RA), and approximately $42 \%$ were on GC (median dose $=5$ $\mathrm{mg}$ ) (range 5-10 mg/day).

Although AFF differs from classic osteoporotic femoral neck or intertrochanteric fractures in several aspects, some authors have reported other risk factors for AFF than antiresorptive therapy. Sato et al previously reported a frequency of $8 \%$ of femoral local- 
ized reaction (localized periosteal thickening of the lateral cortex, beaking) in patients with autoimmune diseases taking BPs and GC [5]. In studies by Thompson et al. [6] and Dell et al. [4], AFF occurred, respectively, in $27 \%$ and $12 \%$ of patients on GC therapy. In addition, Girgis et al. reported that rheumatoid arthritis and use of glucocorticoids were risk factors for AFF [7]. Furthermore, Saita et al found that the use of GC and collagen diseases were risk factors for AFF [OR 13.0 (95\% CI 2.3-74.1) and OR 9.0 (95\% CI 1.6-50.3), respectively] [31]. Of note, most of the patients in the present study had osteopenia both at the femur and lumbar spine according to DXA results, and the continuous treatment with BP was indicated in view of the high risk of fragility fracture. Only two studies in the literature have analyzed the microarchitecture at the distal radius and/or tibia of patients with AFF using HR-pQCT. No data were reported regarding the analysis of their cortical bone by iliac crest histomorphometry.

In contrast with our results, Popp et al. also demonstrated lower stiffness at the distal tibia in AFF patients by HR-pQCT but no decreased cortical volumetric density and thickness [30]. Additionally, Zanchetta et al. did not find any difference of the cortical parameters at the distal radius and tibia compared to healthy controls [29]. These differences could also be explained by differences of the populations at risk of fragility fracture. One patient had AFF in the first 3 months of use of denosumab, but she had previously received BPs for 6 years. Of note, AFF has also been reported as a complication arising from denosumab therapy, but it calls into question whether AFF cannot be derived from the previous use of BPs [32,33]. Interestingly, there was a significant positive correlation of S and F. Load with Ct.Th at the distal radius and tibia, suggesting that the cortical microarchitecture could be a fundamental parameter of bone fragility of the peripheral skeleton in AFF patients. Indeed, stiffness and cortical bone play an important role in bone strength and have been described as independent predictors of fracture $[8,9]$. Characteristically, the patients with AFF have cortical thickening of the femoral diaphysis and local periosteal reaction, raising the possibility that atypical fractures could occur from a cortical stress.

Conversely, this finding was not observed in the present study at the distal radius and tibia after 6 to 12 months after AFF. More than half of the individuals had lower cortical thickness by iliac crest bone histomorphometry. Regarding bone turnover, some studies have measured bone remodeling in the iliac crest or biopsies taken at the fracture site at various intervals after AFF. Consistent with most of these studies, our patients presented with low bone remodeling at the iliac crest, a finding consistent with BP treatment $[1,2,34]$. The mean cortical porosity was lower as measured by histomorphometry than by HR-pQCT. This result can be due to the iliac crest histomorphometric parameters may not be representative of the whole skeleton. Additionally, comparisons between HR-pQCT and histomorphometry were assessed at different anatomical regions and this difference may be secondary to specific site. Other authors have reported either nonsignificant or weak correlations when different sites were compared and is important to emphasized that HR-pQCT analyzed distal peripheral sites. Furthermore, the lack of agreement between histomorphometry and HR-pQCT for cortical porosity is likely related to the size of pores detectable by each technique: the resolution of the HR-pQCT device ( $82 \mu \mathrm{m})$ is insufficient to depict accurate parameters such as small cortical pores. Moreover, cortical thinning associated with cortical porosity in hip fractures, so-called trabecularized cortex, may partly contribute to their similar or lower cortical porosity [35]. This study has some limitations that hamper the interpretation of results, such as the limited number of patients and the cross-sectional design.

\section{Conclusion}

In conclusion, our data demonstrated that among patients with $\mathrm{AF}$, rheumatic diseases and GC use were common. Cortical and strength bone parameters were deteriorated at distal tibia/radius and iliac crest, suggesting the presence of significant bone fragility after 6-12 months of AFF follow-up.

\section{Acknowledgments}

We would like to thank the contribution of the biomedical Jackeline C Alvarenga in performing the HR-pQCT exams.

\section{Compliance with Ethical Standards}

Ethical approval: All procedures performed in studies involving human participants were in accordance with the ethical standards of the institutional and/or national research committee and with the 1964 Helsinki declaration and its later amendments or comparable ethical standards. This study was conducted with the approval of the Research Ethics Committee of the University of São Paulo (Research protocol: 2024803).

\section{Conflicts of Interest}

The authors declare no conflicts of interest related to this article.

\section{Funding}

Conselho Nacional de Desenvolvimento Científico e Tecnológico (CNPq) \# 305556/2017-7 (from RMRP)

\section{Authors Contributions}

a) MOP: conception and design of the study, acquisition of data, drafting the article and revising it critically for publication important intellectual content, final approval of the version to be submitted.

b) DSD: acquisition of data, drafting the article or revising it critically for important intellectual content, final approval of 
the version to be submitted.

c) VJ: acquisition of data, drafting the article or revising it critically for important intellectual content, final approval of the version to be submitted.

d) RMRP: conception and design of the study, acquisition of data, drafting the article or revising it critically for important intellectual content, final approval of the version to be submitted.

\section{References}

1. Shane E, Burr D, Ebeling PR, Abrahamsen B, Adler RA, et al. (2010) Atypical subtrochanteric and diaphyseal femoral fractures: report of a task force of the American Society for Bone and Mineral Research. J Bone Miner Res 25(11): 2267-2294.

2. Shane E, Burr D, Abrahamsen B, Adler RA, Brown TD, et al. (2014) Atypical subtrochanteric and diaphyseal femoral fractures: second report of a task force of the American Society for Bone and Mineral Research. J Bone Miner Res 29(1): 1-23.

3. Schilcher J, Michaelsson K, Aspenberg P (2011) Bisphosphonate use and atypical fractures of the femoral shaft. N Engl J Med 364(18): 1728-1737.

4. Dell RM, Adams AL, Greene DF, Funahashi TT, Silverman SL, et al. (2012) Incidence of atypical nontraumatic diaphyseal fractures of the femur. J Bone Miner Res 27(12): 2544-2550.

5. Sato H, Kondo N, Wada Y, Nakatsue T, Iguchi S, et al. (2016) The cumulative incidence of and risk factors for latent beaking in patients with autoimmune diseases taking long-term glucocorticoids and bisphosphonates. Osteoporos Int 27(3): 1217-1225.

6. Thompson RN, Phillips JR, McCauley SH, Elliott JR, Moran CG, et al (2012) Atypical femoral fractures and bisphosphonate treatment: experience in two large United Kingdom teaching hospitals. J Bone Joint Surg Br 94(3): 385-390.

7. Girgis CM, Sher D, Seibel MJ (2010) Atypical femoral fractures and bisphosphonate use. N Engl J Med 362(19): 1848-1849.

8. Bala Y, Zebaze R, Seeman E (2015) Role of cortical bone in bone fragility. Curr Opin Rheumatol 27(4): 406-413.

9. Roschger P, Rinnerthaler S, Yates J, Rodan GA, Fratzl P, et al. (2001) Alendronate increases degree and uniformity of mineralization in cancellous bone and decreases the porosity in cortical bone of osteoporotic women. Bone 29(2): 185-191.

10. Alvarenga JC, Fuller H, Pasoto SG, Pereira RM (2017) Age-related reference curves of volumetric bone density, structure, and biomechanical parameters adjusted for weight and height in a population of healthy women: an HR-pQCT study. Osteoporos Int 28(4): 1335-1346.

11. Dempster DW, Compston JE, Drezner MK, Glorieux FH, Kanis JA, et al. (2012) Standardized nomenclature, symbols, and units for bone histomorphometry: a 2012 update of the report of the ASBMR Histomorphometry Nomenclature Committee. J Bone Miner Res 28(1): $2-17$.

12. Chavassieux P, Portero Muzy N, Roux JP, Horlait S, Dempster DW, et al. (2019) Reduction of Cortical Bone Turnover and Erosion Depth After 2 and 3 Years of Denosumab: Iliac Bone Histomorphometry in the FREEDOM Trial. J Bone Miner Res 34(4): 626-631.

13. Dos Reis LM, Batalha JR, Muñoz DR, Borelli A, Correa PH, et al. (2007) Brazilian normal static bone histomorphometry: effects of age, sex, and race. J Bone Miner Metab 25(6): 400-406.

14. Melsen F, Mosekilde L (1978) Tetracycline double-labeling of iliac trabecular bone in 41 normal adults. Calcif Tissue Res 26(2): 99-102.
15. Patel RN, Ashraf A, Sundaram M (2016) A typical Fractures Following Bisphosphonate Therapy. Semin Musculoskelet Radiol 20(4): 376-381.

16. Anonymous WHO Study Group (1994) Assessment of fracture risk and its application to screening for post-menopausal osteoporosis. WHO, Geneva, US.

17. Fuller H, Fuller R, Pereira RM (2015) High resolution peripheral quantitative computed tomography for the assessment of morphological and mechanical bone parameters. Rev Bras Reumatol 55(4): 352-362.

18. Boutroy S, Bouxsein ML, Munoz F, Delmas PD (2005) In vivo assessment of trabecular bone microarchitecture by high-resolution peripheral quantitative computed tomography. J Clin Endocrinol Metab 90(12): 6508-6515.

19. Sornay Rendu E, Boutroy S, Munoz F, Delmas PD (2007) Alterations of cortical and trabecular architecture are associated with fractures in postmenopausal women, partially independent of decreased BMD measured by DXA: the Ofely Study. J Bone Miner Res 22(3): 425-433.

20. Vilayphiou N, Boutroy S, Sornay Rendu E, Van Rietbergen B, Chapurlat $\mathrm{R}$, et al. (2015) Age-related changes in bone strength from HR-pQCT derived microarchitectural parameters with an emphasis on the role of cortical porosity. Bone 83: 233-240.

21. Paggiosi M, Eastell R, Walsh JS (2014) Precision of high-resolution peripheral quantitative computed tomography measurement variables: influence of gender, examination site, and age. Calcif Tissue Int 94(2): 191-201.

22. Burghardt AJ, Pialat JB, Kazakia GJ, Boutroy S, Engelke K, et al. (2013) Multicenter precision of cortical and trabecular bone quality measures assessed by highresolution peripheral quantitative computed tomography. J Bone Miner Res 28(3): 524-536.

23. Cohen A, Dempster DW, Müller R, Guo XE, Nickolas TL, et al. (2010) Assessment of trabecular and cortical architecture and mechanical competence of bone by high-resolution peripheral computed tomography: comparison with transiliac bone biopsy. Osteoporos Int 21(2): 263-273.

24. Malluche HH, Faugere MC (1986) Methodology of Mineralized Bone Histology. In: ATLAS of Mineralized Bone Histology. Karger S, Basel, Switzerland, p. 17-24.

25. Recker RR, Kimmel DB, Dempster D, Weinstein RS, Wronski TJ, et al. (2011) Issues in modern bone histomorphometry. Bone 49(5): 955-964.

26. Vedi S, Kaptoge S, Compston JE (2011) Age-related changes in iliac crest cortical width and porosity: a histomorphometric study. J Anat 218(5): 510-516.

27. Arlot ME, Delmas PD, Chappard D, Meunier PJ (1990) Trabecular and endocortical bone remodeling in postmenopausal osteoporosis: comparison with normal postmenopausal women. Osteoporos Int 1(1): 41-49.

28. Ott SM (2008) Histomorphometric measurements of bone turnover, mineralization, and volume. Clin J Am Soc Nephrol 3 (3 Suppl): 151-156.

29. Zanchetta MB, Diehl M, Buttazzoni M, Galich A, Silveira F, et al. (2014) Assessment of bone microarchitecture in postmenopausal women on long-term bisphosphonate therapy with atypical fractures of the femur. J Bone Miner Res 29(4): 999-1004.

30. Popp KL, Caksa S, Martinez-Betancourt A, Yuan A, Tsai J, et al. (2019) Cortical Bone Material Strength Index and Bone Microarchitecture in Postmenopausal Women with Atypical Femoral Fractures. J Bone Miner Res 34(1): 75-82.

31. Saita Y, Ishijima M, Mogami A, Kubota M, Baba T. et al (2015) The incidence of and risk factors for developing atypical femoral fractures in Japan. J Bone Miner Metab 33(3): 311-318.

32. Papapoulos S, Lippuner K, Roux C, Lin CJ, Kendler D, et al (2015) The effect of 8 or 5 years of denosumab treatment in postmenopausal 
women with osteoporosis:results from the FREEDOM Extension study. Osteoporos Int 26(12): 2773-2783.

33. Khow KS, Yong TY (2015) Atypical femoral fracture in a patient treated with denosumab. J Bone Miner Metab 33(3): 355-358.

34. Bala Y, Farlay D, Chapurlat RD, Boivin G (2011) Modifications of bone material properties in postmenopausal osteoporotic women long-term treated with alendronate. Eur J Endocrinol 165(4): 647-655.

\section{ISSN: 2574-1241}

DOI: $10.26717 /$ BJSTR.2020.26.004385

Rosa MR Pereira. Biomed J Sci \& Tech Res

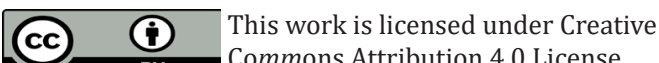

Submission Link: https://biomedres.us/submit-manuscript.php
35. Boutroy S, Vilayphiou N, Roux JP, Delmas PD, Blain H, et al. (2011) Comparison of $2 \mathrm{D}$ and $3 \mathrm{D}$ bone microarchitecture evaluation at the femoral neck, among postmenopausal women with hip fracture or hip osteoarthritis. Bone 49(5): 1055-1061.

$\begin{array}{ll}\text { BIOMEDICAL } & \text { Assets of Publishing with us } \\ \text { RESEARCHES } & \text { - Global archiving of articles } \\ \text { - Immediate, unrestricted online access } \\ \text { - Rigorous Peer Review Process }\end{array}$

